\title{
应用化学一流本科专业建设的探索与实践
} 以西安交通大学应用化学专业为例

李银环 ${ }^{*}$, 高瑞霞, 张莉, 张志成

西安交通大学化学学院, 西安 710049

摘要: 西安交通大学应用化学专业坚持以本为本, 突出理工交叉, 全力打造一流应用化学专业, 从学科定位、人才 培养理念、课程教材改革、师资队伍建设、教学科研融合等全方位创新教学实践, 培养家国情怀浓厚、数理基础扎 实、学科深度交叉、创新能力突出、能够传承 “西迁精神” 的领军人才。

关键词: 应用化学; 一流专业建设; 教学改革

中图分类号: G64; O6

\section{Exploration and Practice on the Construction of First-Class Applied Chemistry Major: Taking Applied Chemistry Major in Xi'An Jiaotong University as an Example}

\author{
Yinhuan Li ", Ruixia Gao, Li Zhang, Zhicheng Zhang
}

School of Chemistry, Xi'an Jiaotong University, Xi'an 710049, China.

\begin{abstract}
The applied chemistry major of Xi'an Jiaotong University adheres to undergraduate education, emphasizes the intersection of science and engineering, and strives to construct a first-class applied chemistry major. By innovatively teaching students in all aspects, including subject orientation, talent training concept, curriculum and teaching material reform, teacher team construction, and teaching and research integration, it has cultivated the leading talents with strong patriotism, solid scientific and mathematical foundation, in-depth interdisciplinary, outstanding innovation ability, and the ability to inherit the "westward relocation spirit".
\end{abstract}

Key Words: Applied chemistry; First-class major construction; Teaching reform

国势之强由于人, 人材之成出于学。高等学校作为培养高素质人才的重要基地, 肩负着培养高 素质人才并将其输向社会的重任 ${ }^{[1]}$ 。本科教育是具有战略地位的教育、是纲举目张的教育, 而专业 是建设一流本科、培养一流人才的 “四梁八柱” ${ }^{[2]}$ 。为此, 教育部提出做强一流本科、建设一流专 业、培养一流人才, 全面振兴本科教育, 提高高校人才培养能力, 实现高等教育内涵式发展 ${ }^{[3]}$ 。如何 结合国家需求及学校特色, 建设一流专业、培养一流人才, 是高等学校持续探索的时代命题 ${ }^{[4]}$ 。交通 大学化学系始建于1928年, 随交大主体西迁后, 先后支撑学校创建电气工程、能源动力与工程、高 分子材料等专业。西安交通大学应用化学专业自1999年设立以来, 坚持 “起点高、基础厚、要求严、 重实践” 的人才培养特色, 围绕 “面向未来、适应需求、引领发展、理念先进、保障有力”一流专

收稿: 2021-07-25; 录用: 2021-07-28; 网络发表：2021-09-07

“通讯作者, Email: liyh@xjtu.edu.cn

基金资助：西安交通大学 “名师、名课、名教材”建设工程培育项目(2018 年) 
业的建设要求, 根植 “胸怀大局、无私奉献、弘扬传统、艰苦创业” 的西迁精神, 历经 20 余载披荆 斩棘, 形成了鲜明的专业特色和优势, 为全国, 尤其是中西部地区发展培养了大批人才, 于 2019 年 入选陕西 “双万计划” 省级一流本科专业建设点, 2020 年入选教育部 “双万计划” 国家级一流本科 专业建设点。西安交通大学应用化学专业以服务国家和社会重大需求为导向, 深化应用化学专业综 合改革, 加强师资队伍和基层教学组织建设, 依托高水平科研平台, 培养创新能力突出、具有国际 竞争力的一流领军人才。

\section{1 以国家需求为导向, 科学定位, 形成了鲜明的专业特色}

西安交通大学应用化学专业以服务国家和社会重大需求为导向, 聚焦绿色合成、新能源、高分 子等方向, 与工科能动、电气、机械等优势专业交叉融合, 培养家国情怀浓厚、数理基础扎实、学 科深度交叉、创新能力突出的一流人才。

基于上述培养定位, 西安交通大学应用化学专业一直秉承 “起点高、基础厚、要求严、重实践、 强创新” 的人才培养特色, 注重理工交叉融合, 形成特有的 “三早一交叉”一流人才培养模式。专 业坚持加强基层教学组织建设和师资队伍建设, 打造了一支由大师引领、多学科交叉、科教融合的 卓越师资团队。为强化化学基础及应用实践能力相结合, 专业依托省部级重点实验室、化学研究院、 化学实验教学示范中心、化学创新实验实践平台等, 创建一流的教学平台。

\section{2 深化应用化学专业综合改革的主要举措}

打造一流的西安交通大学应用化学专业, 必须坚持国家人才需求导向, 明确专业定位, 保持特 色鲜明, 及时发现建设一流专业过程中的短板问题并及时解决不足之处。西安交通大学应用化学专 业在建设一流专业的实践与探索过程中, 从人才培养理念、课程教材建设、教学手段运用、厚植家 国情怀等方面深入推进专业改革与发展。

\section{1 突出 “理工交叉” 培养理念, 推进 “新工科” 建设}

西安交通大学应用化学专业在教学过程中以化学为中心, 以新能源、人工智能、节能减排等领 域的关键问题为牵引, 突出 “夯实化学基础, 理工交叉培养” 育人特色, 推动应用化学 “新工科” 建设。

专业实施本科生学业导师制度, 创新 “三早一交叉” 的学生培养模式, 即早接触、早实践、早 科研, 夯实化学理论基础的同时注重理工交叉培养。学生从大一小学期进入多学科交叉融合实践教 学平台, 了解化学专业及其与化学交叉专业(材料、生命、医学、能动、电气等)各类实践项目及测试 技术等, 通过 “早接触” 开拓学生的视野, 提高学生的想象力。大二学生进入不同课题组, 通过 “早 实践, 了解化学相关科学研究方向、研究思路等, 结合自己的兴趣爱好, 初步确定自己喜欢并适合 的研究方向。大二小学期、大三全年学生进入科研训练环节, 这期间学生通过各类创新创业项目、 实验实践大赛、导师课题等进入具体科学研究阶段。大四学生进入毕业设计环节, 该阶段在前期研 究基础上培养学生独立开展课题的能力, 包括问题的提出、解决思路、方案与措施等, 帮助学生尽 快适应和参与科学研究的各个环节, 做好本科生培养和研究生培养相衔接。

\section{2 立足立德树人根本任务, 建设应用化学课程思政示范专业}

专业是人才培养的基本单元, 而课程是人才培养的重要载体。通过加强课程思政建设, 充分挖 掘课程中蕴含的思想政治教育资源, 实现专业教育与思想政治教育的紧密融合, 让课程更好地发挥 育人功能, 实现 “润物细无声” 的育人效果。应用化学专业坚持以立德树人为根本任务, 基于 “以 学生为中心” “以产出为导向” 的理念, 围绕专业课程教学目标, 进行系统设计和实施, 深入挖掘课 程育人功能, 突出世界观和方法论教学, 突出学生综合评价能力、学科思维能力和批判创新能力的 培养, 推动专业教学由知识导向型向能力和素质导向型转变。 
在应化专业全体教师的共同努力下，专业实现了专业教育与思政教育有机融合，2020年建成了 西安交通大学课程思政示范专业, 获批陕西省课程思政本科示范课程 $1 门 、$ 西安交通大学课程思政本 科示范课程8门, 其中 $3 门$ 门课程思政教学案例被选入《西安交通大学课程思政教学案例(2019)》 ${ }^{[5]}$ 。同 时, 专业基于省级实验教学平台及虚拟仿真实验项目, 深挖实践类课程的育人元素, 建成 “有机化 学实验” “无机化学实验” 等主题突出、特色鲜明的实践类课程思政示范课。通过阐明世界古代化 学史、普及实验前生态安全教育、实验中引入绿色设计、教学中适时宣传国家环保和生态文明建设 的政策、阐述化学的发展趋势、增设设计性实验等多种形式进行 “思政渗透” , 培养学生的爱国主 义精神、民族自豪感和自信心, 帮助学生树立生态文明理念, 增强生态保护意识和能力, 培养学生 优秀的专业品质和突出的专业能力。

\section{3 加强课程教材建设, 推动课堂教学革命}

西安交通大学应用化学专业主干课程实行责任教授制, 定期开展教研活动, 以教学改革促进教 材建设, 常总结、常改编、常更新, 引入课程思政元素, 结合在线课程资源加强新型态教材建设。 实践 “大班授课, 小班研讨” 讨论互动式教学新模式, 利用 “翻转课堂” 及PBL教学等多种教学手 段, 融合雨课堂、微助教等多种信息技术提升学生课堂参与度, 同时参与程度和表现好坏计入过程 考核中, 通过强化过程考核, 采用多维度、多阶段考核模式, 期末考试成绩占比不高于最终成绩 $70 \%$ 等措施促使学生将学习过程放在整个学期, 而不是期末搞突击, 与此同时, 作为授课教师也需要根 据学生情况精心设计课程内容以及授课模式和方法, 积极推动课堂教学改革, 从而适应新形势下教 育教学发展。

\section{4 融合信息教学手段, 打造线上线下一流课程}

一流教学条件是一流专业建成的必要保障, 西安交通大学应用化学专业经过多年实践与探索, 逐渐形成属于自己的特色教学模式。学院以新冠疫情防控为契机, 依托学校 “思源学堂” 平台, 结 合中国大学MOOC、雨课堂、学堂在线等平台, 积极开展在线授课; 学校同时配有相关政策鼓励教 师广泛开展线上线下混合式教学, 依托超星、智慧树等公司建设多平台在线课程, 融合课程思政, 着力打造课堂教学效果卓越的一流课程。

\section{5 厚植学生家国情怀, 培育 “西迁精神” 新传人}

交通大学在史诗级的西迁历程及迁校后的发展建设过程中产生了 “胸怀大局、无私奉献、弘扬 传统、艰苦创业” 的西迁精神。西安交通大学应用化学专业潜心培养能够认真学习和弘扬这种艰苦 奋斗精神的优秀毕业生, 并在培养环节中不断充盈 “西迁精神” 的新时代内涵。

在化学专业核心课中建设一批示范课程, 与思政课程相结合, 通过 “双院制” 育人模式和 “四 个一百” 育人活动, 引导学生面向国家战略需求、世界科技前沿、国民经济主战场、人民生命健康, 将爱国主义、集体主义、英雄主义、乐观主义等融入西迁精神新传人的培育过程中。应用化学专业 坚持把立德树人融入思想道德教育、文化知识教育、社会实践教育各环节, 贯穿基础教育、职业教 育、高等教育各领域, 促使自强不息、艰苦奋斗的思想精髓与学生自身价值观的塑造融为一体, 形 成了高水平的人才培养体系 ${ }^{[6]}$ 。

\section{3 加强师资队伍建设, 保障课堂教学质量}

应用化学专业坚持强化基层教学组织建设和师资队伍建设, 不断通过引进、培养和校内外选聘 等多种方式, 吸纳杰出人才, 加强师资队伍建设。近五年学院引进国家级青年人才 1 人, 外籍教师 3 人, 西安交通大学青年拔尖人才 16 人。学院坚持强化师德师风建设, 落实以本为本, 严明教师职责, 实行师德师风一票否决制。作为应用化学系基层教学组织以及五大二级学科(无机、分析、有机、物 化、高分子)教学团队围绕提升教学质量, 广泛持续开展教学模式与方法、教学内容更新等教学研究 活动, 教师队伍的专业教学能力和整体素质水平都有显著提升 ${ }^{[7]}$ 。 


\section{1 注重基层教学组织建设, 稳步提升教学质量}

学院设置教学指导委员会和教学督导委员会, 教学指导委员会负责教学政策制定、教师选聘等 环节; 教学督导委员会主要负责教师课堂质量。按照二级学科方向组建 5 个基层教学团队, 实行责任 教授负责制, 选聘优秀人才充实教学队伍。各团队坚持集体备课、每两周开展一次教研法活动, 内 容涉及名师引领讲堂、教学理念和教学经验交流、示范课展演、难点讲授研讨、新教师演练等, 通 过名师 “传帮带” 和同行互助并行, 以及承担教改项目, 开展教学改革、教材建设和 “一流课程” 建设等, 促进教师全面发展。

\section{2 以领军学者为引领, 打造教学科研双赢教学团队}

近年来, 应用化学专业坚持以领军学者为引领, 引进和内培重点发展领域青年拔尖人才等各层 次人才, 加强基层教师教学科研能力培养, 邀请国际师资授课及学术交流, 构建层次清晰、充满活 力、组织健全的师资队伍。同时, 与行业龙头企业及科研院所共同打造化学实践教育和创新创业教 育体系, 建成一流化学交叉实践创新共享平台, 积极将最新科研成果转化为实践教学案例(见表1), 打造教学科研双赢教学团队。与京博农化科技有限公司等优秀企业共建双链融合创新平台, 推动产 学研深度合作育人。显著提高实验技术人员科研成果转化能力, 将一批最新科研成果转化为实践教 学案例。本科生进入重点实验室、科研院所以及教师课题组开展科学研究比例不断提高。

表1 最新科研成果转化为实践教学案例汇总

\begin{tabular}{|c|c|c|}
\hline 序号 & 最新科研成果转化成实验教学项目 & 使用课程 \\
\hline 1 & 氧化还原法制备石墨烯 & 综合化学实验 \\
\hline 2 & 两性表面活性剂BS-12的合成与评价 & 综合化学实验 \\
\hline 3 & 金属酞菁的合成及光谱特性研究 & 综合化学实验 \\
\hline 4 & 2-苯基吡啶Pt配合物磷光发光分子的合成与光物理表征 & 综合化学实验 \\
\hline 5 & 局部麻醉剂苯佐卡因的合成 & 综合化学实验 \\
\hline 6 & 苯乙烯与甲基丙烯酸甲酯共聚物的合成及其表征 & 综合化学实验 \\
\hline 7 & 苯频哪醇光化学合成 & 有机化学实验II \\
\hline 8 & $\mathrm{TiO}_{2}$ 纳米粉体的合成、表征 & 无机化学实验II \\
\hline 9 & Co配合物制备及光谱序测 & 无机化学实验II \\
\hline 10 & 明矾的制备、鉴定与水的净化 & 无机化学实验II \\
\hline 11 & 光敏材料三草酸合铁酸钾的制备、组成测定及光敏特性 & 无机化学实验II \\
\hline 12 & 纳米银的制备、形貌表征及光谱特性 & 无机化学实验II \\
\hline 13 & 碳量子点制备及荧光性能研究 & 无机化学实验II \\
\hline 14 & 共沉淀法制备 $\mathrm{Fe}_{3} \mathrm{O}_{4}$ 及磁流体制备 & 无机化学实验II \\
\hline 15 & $\mathrm{C} @ \mathrm{Fe}_{3} \mathrm{O}_{4}$ 的制备及污水处理 & 无机化学实验II \\
\hline 16 & 铝合金图形化及阳极氧化 & 无机化学实验II \\
\hline 17 & 微米 $\mathrm{Cu}_{2} \mathrm{O}$ 的可控化合成、表征及光降解研究 & 无机化学实验II \\
\hline 18 & 金溶胶的制备及其光学性质与界面自组装 & 物质结构与性质一一无机篇 \\
\hline
\end{tabular}

\section{4 建设成效}

西安交通大学应用化学专业秉承 “起点高、基础厚、要求严、重实践” 的办学特色, 建设绿色 合成与新能源为特色的 “新工科” 课程体系, 打造德才兼备的一流师资队伍, 与校企联合建设科教 融合创新实践平台、未来技术学院, 培养创新能力突出、具有国际竞争力的一流人才。经过近几年 的不断实践与探索, 应用化学专业在人才培养、课程教材建设、厚植家国情怀等方面都取得了长足 进步。 
(1) 充分调动学生的学习积极性、创新主动性, 基础知识扎实, 实践能力、科研能力和创新能力 明显增强, 学生在升学及就业方面获用人单位普遍好评。本专业生产实习连续 10 年被评为校级优秀。 近三年, 在校本科生获批国家、省部级大学生创新项目 18 项, 获得省部级以上各类奖项 20 余人次, 其中 “退役锂离子电池带电拆解与余热回收一体化设计” 获全国大学生节能减排社会实践与科技竞 赛一等奖。近三年 $75 \%$ 的毕业生进入国内外著名高校、科研院所深造, 参与发表Angew. Chem. Int. Ed.、 J.Am. Chem. Soc. 等化学顶级期刊40余篇。毕业生就业范围广, 分布在研究机构、企事业单位、政府 机关等, 其中以进入西安交通大学、南方科技大学、阿卜杜拉国王科技大学等研究型高校及研究机 构工作为主, 占比约 $36.79 \%$ 。截止目前已培养毕业生入选教育部青年长江学者等国家级人才 12 人。

(2) 深化应用化学专业教学改革, 教学质量明显提升。通过持续加强教材体系建设, 目前共出版 教材 30 余部, 其中 《有机化学》等国家级教材 10 余部、专著 4 部、《无机与分析化学》等新型态教材 4 部、《Medical Chemistry》等国际化教材4部, 总计发行逾百万册, 使用高校 20 余所, 反响良好。通 过融合信息教学手段, 打造线上线下国家级一流课程 $3 门$ 门, 省级一流课程5门, 省级课程思政示范课 $1 门$ 门 应化专业获批校级课程思政示范专业。将教育教学新形态、新方法与专业课程有机融合, 实 现全部专业课程线上教学实践, 13 门MOOC课程在爱课程、学堂在线、好大学等网络平台上线, 其 中结合国家 “一带一路” 战略建成了1门国际化课程 “Analytical Chemistry” ${ }^{[8]}$, 线上课程资料点击 30 余万次。建成陕西省虚拟仿真实验中心。

(3) 厚植家国情怀, 培育 “西迁精神” 新传人。交通大学西迁是国家调整高等教育战略布局的重 大举措, 开发大西北成为全校共同心声, 实践证明: 交通大学的西迁给西北地区带来了新的发展动 力, 这得益于西迁后的交通大学——西安交通大学培养出来的学生很好地传承了 “西迁精神” 的内 涵, 以及秉承了西安交通大学 “扎根西部、服务国家、世界一流” 的办学宗旨, 形成了浓厚的家国 情怀, 无形中增强了学生的职业认同感、强化了学生的使命担当, 到祖国最需要的地方去。促使了 应化专业学生 $80 \%$ 以上毕业生选择扎根中西部, 服务国家。

\section{5 未来专业建设规划}

尽管应用化学专业建设已取得一些成绩, 但在专业建设过程中我们也发现了一些问题: 理论教 学与实践脱节; 对学生思维方法、解决问题能力培养不足; 人文素质培养不足, 忽视内在潜力的激 发, 导致课程学习育人效率较低; 不同课程系统性、互补性有待提高; 课程设置中育人成效方面考 虑不足。

针对这些问题，未来专业建设将从以下几个方面着手建设：

（1）强化实践育人, 将基础理论贯穿基础实验、专业实验、综合实验、科研训练、毕业设计、生 产实习等各个环节;

(2) 通过开展项目式、案例式、基于问题式等教学模式改革, 培养学生逻辑思维方式, 以及系统 解决问题的能力;

(3) 通过课程思政, 借助人文社科育人平台, 激发学生内在学习动力和学习兴趣, 实现自我教育 和提升, 提高育人效率。

(4) 梳理化学类课程的知识内容, 去除重复的部分, 不同课程紧密衔接, 大幅度提高授课效率。

(5) 高年级专业课程强化创新性分析问题、系统化解决问题的能力培养, 强调在实验室和生产线 上实现理论学习。

致谢: 感谢兄弟院校、社会各界对西安交通大学化学学院一流专业建设的支持; 感谢西安交通大学的资助。 
[1] 纪敏, 孟长功, 姜文风, 吴硕, 赵艳秋. 大学化学, 2021, 36 (5), 2003036.

[2] 教育部. 关于一流本科课程建设的实施意见. [2019-10-30]. http://www.moe.gov.cn/srcsite/A08/s7056/201910/t20191031_406269.html

[3] 教育部: 将实施一流专业建设“双万计划”. [2020-09-18]. http://www.moe.gov.cn/jyb_xwfb/xw_fbh/moe_2069/xwfbh_2018n/xwfb_20180622/mtbd/201806/t20180625_340918.html

[4] 杨屹, 陈咏梅, 许家喜, 白守礼, 刘建军, 孙艳芝, 漂红, 陆军, 冯拥军, 王涛, 等. 大学化学, 2021, 36 (5), 2008088.

[5] 杨建科. 西安交通大学课程思政教学案例(2019). 西安: 西安交通大学出版社, 2019.

[6] 习近平. 在全国教育大会上的讲话. [2020-09-18]. http://www.moe.gov.cn/jyb_xwfb/s6052/moe_838/201809/t20180910_348145.html

[7] 陈波, 王媛媛, 田阳. 大学化学, 2021, 36 (5), 2009068.

[8] 学堂在线: Analytical Chemistry. [2020-09-25]. https://www.xuetangx.com/course/xjtu0703fu090101intl?channel=search_result

\section{欢迎订阅《大学化学》}

《大学化学》是由教育部主管, 北京大学和中国化学会共同主办的教育研究性学术刊物。以促进深化大 学化学教育改革为宗旨, 为提高我国化学教学水平服务。读者对象为高等学校化学教师、研究生、本科生, 中学化学教师, 对化学有浓厚兴趣的中学生, 以及化学教育领域的各级管理人员和其他岗位上的化学工作 者。主要栏目有: 今日化学、教学研究与改革、知识介绍、化学实验、师生笔谈、自学之友、大学化学先修 课程、竞赛园地、未来化学家、科普、国外化学教育、化学史以及专题讨论等。

《大学化学》现为月刊, 大 16 开本, 亚光铜版纸印刷。 2022 年每本定价 30.00 元, 全年出版 12 期, 共 360.00 元。

全国各地邮局均可订阅, 邮发代号: 82-314。为方便读者订阅, 本刊编辑部全年办理邮购业务。

地址: 北京大学化学学院《大学化学》编辑部

邮编: 100871

电话: +86-10-62751721

邮箱: dxhx@pku.edu.cn

网址: http://www.dxhx.pku.edu.cn 